\title{
MORPHOLOGICAL DIVERSITY OF WEEDY RICE ACCESSIONS COLLECTED IN AMPARA DISTRICT
}

\author{
U.I.P. Perera*, W.A.D.P.R. Ratnasekera and S.G.J.N. Senanayake \\ Department of Agric. Biology, University of Ruhuna, Sri Lanka \\ *isharauip@gmail.com, Tele:++940718080985
}

\begin{abstract}
Weedy rice is becoming common in most rice growing areas in Sri Lanka. It is variable in almost all the vegetative and reproductive characteristics and tends to have low tillering ability, easy shattering, long awns and higher dormancy in some variants. In addition, weedy rice may contain important genes which can be incorporated into the cultivated varieties. In order to ascertain the diversity for its possible utilization in rice crop improvement, morphological characters of weedy rice accessions were observed in three locations in Ampara district. Characters were observed from 50 individuals with at least $5 \mathrm{~m}$ distance between plants. A significant difference was observed in weedy rice plants observed at Thottama for plant height while at Lahugala significant differences were observed for tiller number (3.22) and number of panicles (2.54). 58\% of observed panicles had awns and purple colored long awns were the most prominent. In addition, white colored long awns, purple colored medium sized awns and white colored medium sized awns were present. The plants observed at Thottama showed higher number of panicles from relatively shorter plants. The existence of great diversity in the morphology indicates the presence of other related agronomic, physiological aspects for their selection and adoption.
\end{abstract}

Keywords: Weedy rice, Diversity

\section{INTRODUCTION}

Weedy rice (Oryza sativa f. spontanea) is taxonomically classified as the same species as cultivated rice (O. sativa) and becoming a serious problem in rice growing areas all over the world, particularly in South and South-east Asia, South and North America, and southern Europe (Ferrero et al., 1999; Mortimer et al., 2000). The origin of weedy rice in Asia is as yet unclear though it is thought that they are natural hybrids of cultivated rice $(O$. sativa $)$ and wild rice species (O. rufipogon and O. nivara). Weedy rice was first reported in 1997 in Ampara district of Sri Lanaka. Morphologically, weedy rice is highly variable and appears to be an intermediate between wild and cultivated rice. Most weedy rice ecotypes are morphologically similar to cultivated rice varieties from the seedling to the reproductive stage that they are difficult to recognize during the periodic weeding of the crop. Weedy rice is variable in almost all the vegetative and reproductive characteristics with each other.

Weedy rice seeds usually have a red pericarp, although some strains have white pericarps (Arrieta-Espinozal et al. 2005). It is characterized by early tillering plus flowering than cultivated rice, and anthocyanin pigmentation of different plant parts such as collar, ligule, grain apiculus, sigma and awns (Cho et al 1995; Suh et al 1997). Since weedy rice is considered as a natural hybrid between cultivated rice and wild rice it may be possible to use as a bridge to transfer gene from secondary genepool to cultivated rice. Weedy rice may also contain important genes which can be incorporated into the cultivated varieties. The study was carried out to determine morphological diversity of weedy rice populations within Ampara district and to explore the possible use of them in rice crop improvement in breeding programmes.

\section{MATERIAL AND METHODS}

An extensive survey was carried out at the rice-planting areas of Ampara District and three weedy rice infested locations were purposely selected as sampling sites where weedy rice was found by farmers in different years. The study area, Ampara belongs to Low country Dry 
Zone having a mean rainfall of less than $1750 \mathrm{~mm}$. The selected locations were Thottama, Akkaraipattu and Lahugala where a higher weedy rice infestation was observed (Fig.1). Information on the occurrence of weedy rice during the past 12 years was obtained by field investigations and questionnaires to local farmers who owned the rice fields with weedy rice and to regional agricultural extension officers. Observations were taken from weedy rice plants from rice fields of these locations in Yala season, 2009.

Plant height, panicle length, leaf length, leaf width, presence of awn, awn color, awn length, number of tillers and number of panicles were observed from 50 individuals with at least $5 \mathrm{~m}$ distance between plants from each location. The observations were recorded according to the rice descriptors published by International Rice Research Institute in 1980.

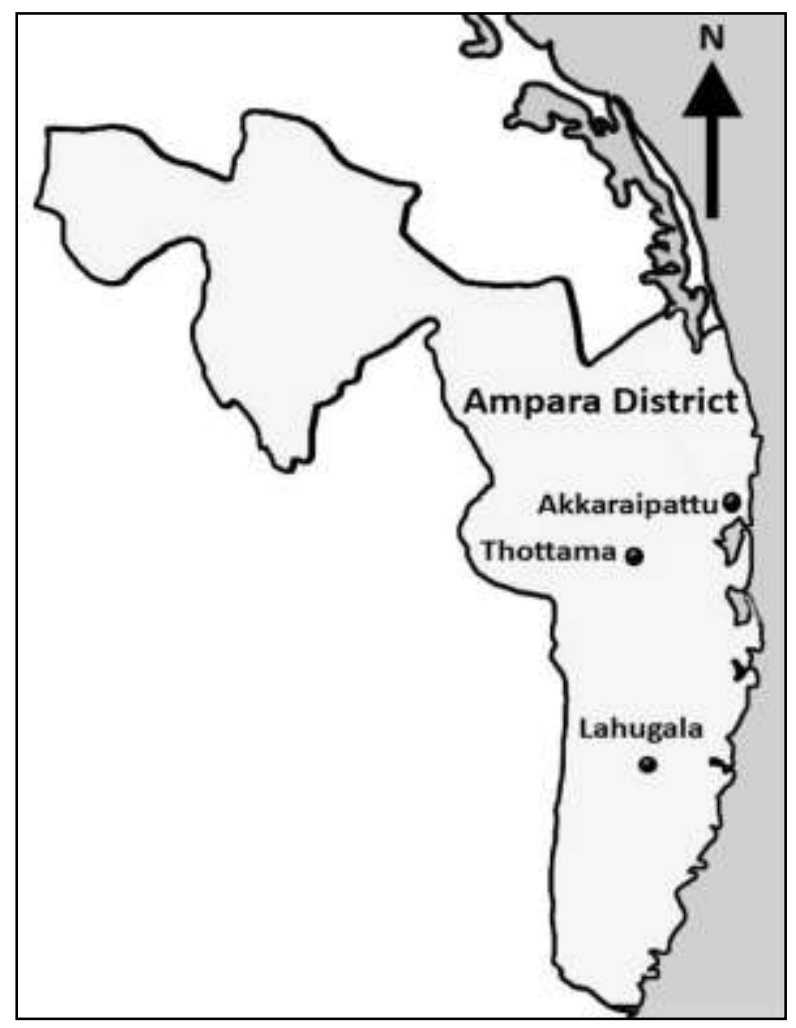

Figure 1: Map of Ampara district

\section{RESULTS AND DISCUSSION}

A higher morphological variation was observed for the characters of weedy rice plants between and within the selected locations of Ampara district. According to the questionnaire survey with the farmers, weedy rices are good seed producers with early and heavy shattering and have a superior vigor compared to cultivated rice.

Significantly shortest plants were observed at Thottama (144.294) weedy rice populations (Fig. 2) compared to other locations. The plants observed at Akkaraipattu (149.266) and Lahugala (147.132) were much taller and no significant difference was showed among them. The leaf length of varied from $38.8 \mathrm{~cm}$ to $58.8 \mathrm{~cm}$ and no significant differences were observed from the locations for leaf length (Fig.2). 


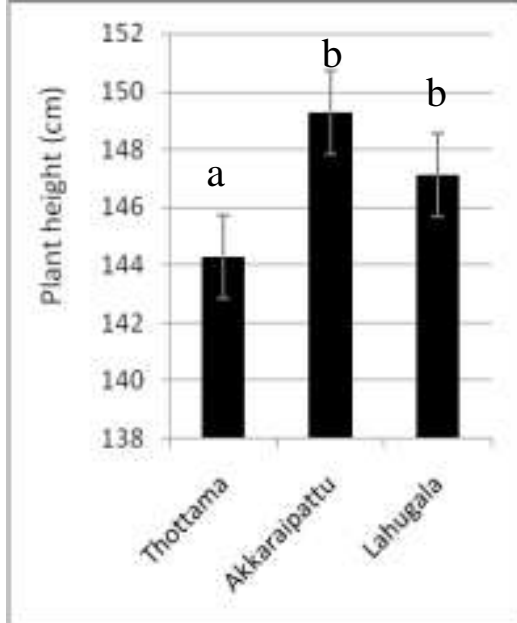

(a)

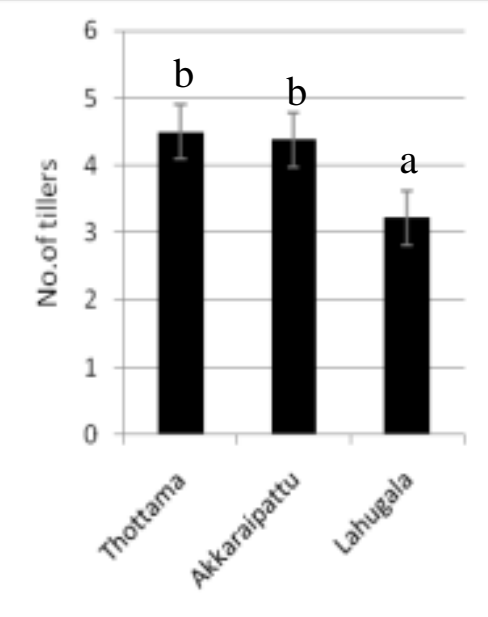

(b)

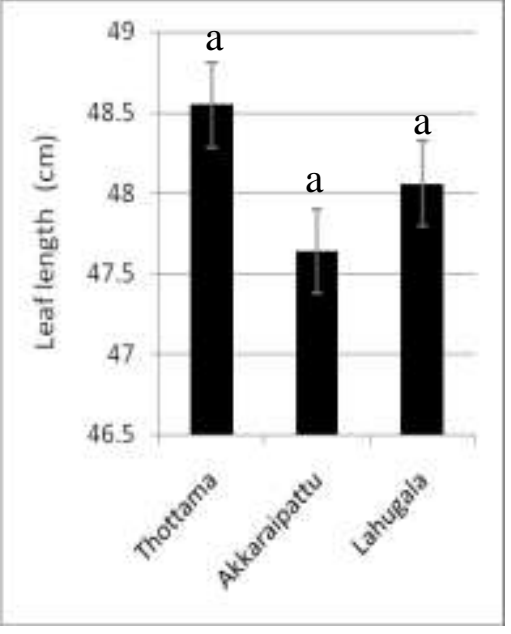

(c)

Figure 2: Variation of the means of plant growth characters

(a) Variation of the means of plant height

(b) Variation of the means of number of tillers

(c) Variation of the means of leaf length

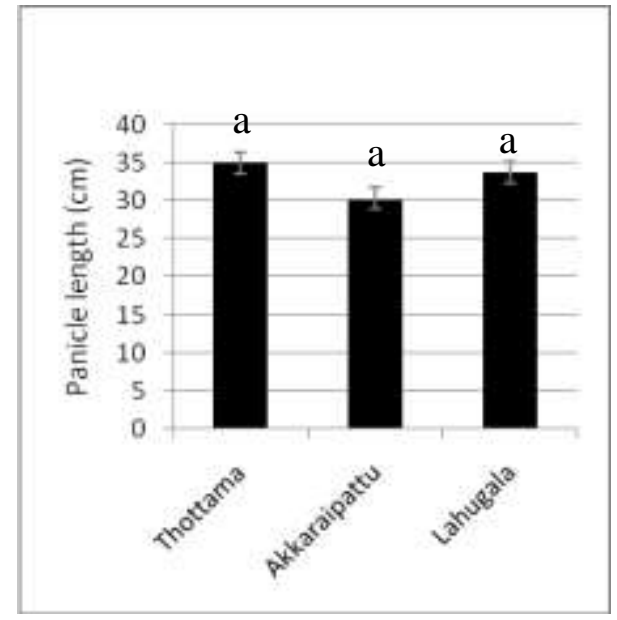

(a)

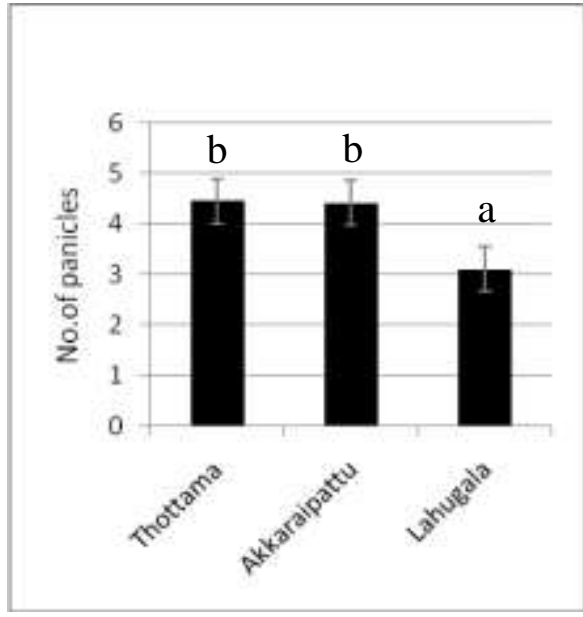

(b)

Figure 3: Variation of the means of yield characters

(a)Variation of the means of number of panicles

(b) Variation of the means of number of panicles

At Lahugala, significant differences were observed for tiller number (3.22) and number of panicles (2.54) having a comparatively a lesser number than other locations. The highest number of tillers (4.5) and panicles (3.8) was observed at Akkaraipattu. (Fig 2, Fig 3) But the panicle length (30.28) was relatively shorter in Akkaraipattu, compared to the plants observed at Lahugala and Thottama (Fig 3) although not significant. 


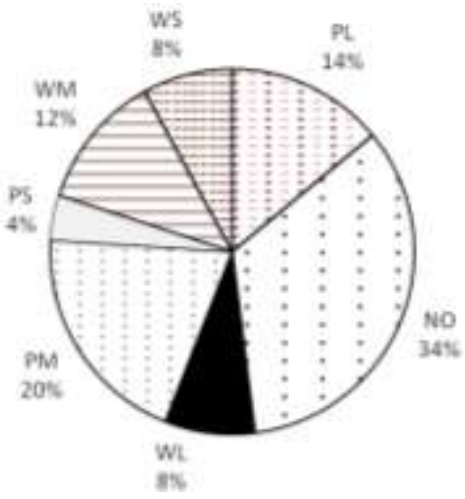

Thottama

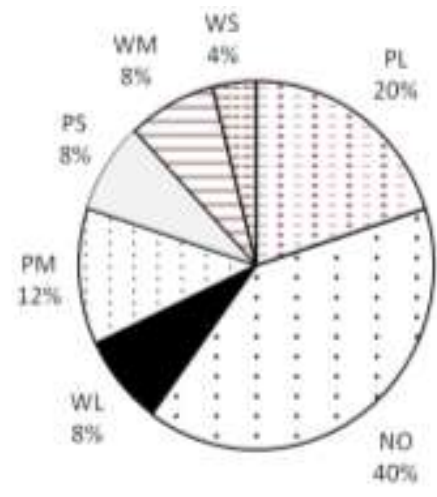

Akkaraipattu

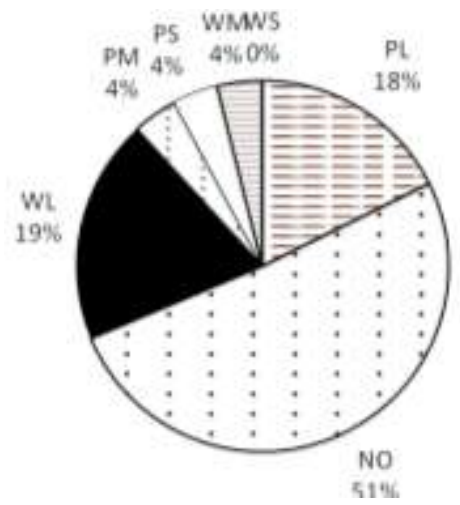

Lahugala

Figure 4: Variation of the awn color and size within locations. PL-Purple colored long awn, PM-Purple colored medium sized awn, PS-Purple colored short awn, WL-White colored long awn, WM- White colored medium sized awn, WS- White colored short awn, NO-Awnless

A higher variation was observed in weedy rice seeds among and within the observed locations of Amapara district. Weedy rice seeds with medium-grain awnless are difficult to distinguish and separate from those of some cultivated varieties. The plants observed from the study showed grains with and without awns. Also the size and the color of the awn were highly variable. The observed weedy rice grains with awns were classified according to the color such as white, purple, bicolor and the size of awn such as short, medium and long. The average awned seeds observed were $60 \%$ of the total panicles in Ampara district. 64\% and $62 \%$ of them had awns in Thottama and Akkaraipattu respectively, while $51 \%$ were awnless in Lahugala. Purple colored medium sized awns were the most prominent $(20 \%)$ from the awned seeds in Thottama and purple colored long awns (14\%) and white colored medium sized awns (12\%) were also present. At Akkaraipattu, white colored awns were less prominent and $40 \%$ of awnless seeds were observed (Fig 4 ).

\section{CONCLUSION}

There was a higher morphological diversity among weedy rice plants within selected locations. Genetic uniformity through the improvement of rice breeding programmes is a key issue. The plants observed at Thottama showed a higher number of panicles from relatively shorter plants which can be considered as a favorable phenotypic character for selection. This higher variation is important for the breeders for selection of favorable characters such as higher number of productive panicles, shorter plants, long panicles, awnless grains etc to improve rice varieties. At present genetic uniformity through the improvement of rice breeding programmes is a key issue. The diversity observed among weedy rice populations is a good source to address this situation.

\section{REFERENCES}

Cho, Y.G., Blair, M.w,:Panaud, O. and McCouch,S.R (1995). Cloning and mapping of variety specific rice genomic DNA sequences amplified length fragmentpolymorphisms (AFLP)from silver strained polyacrylamide gels. Genome39:373-378.

Ferrero A, Vidotto F, Balsari P, Airoldi G. (1999). Mechanical and chemical control of red rice (Oryza sativa L. Var. sylvatica) in rice (Oryza sativa L.) per-planting. Crop Protection 18: 245-251.

Mortimer M, Pandey S, Piggin C. (2000). Weedy rice: approaches to ecological appraisal and implications for research priorities. In: Baki BB, Chin DV, Mortimer M, eds. Proceedings of Wild and Weedy Rice in Rice Ecosystems in Asia. A review. Los Banos, Philippines: International Rice Research Institute, 97-105. 
Suh, H.S.; Sato, Y.I. and Morishima, H. (1997. Genetic characterization of weedy rice (Oryza sativa L.) based on morpho-physiology, isozymes and RAPD markers. Theoretical Applied Genetics 94:316321. 